\title{
Childhood Favorable Prognosis Hodgkin Lymphoma
}

National Cancer Institute

\section{Source}

National Cancer Institute. Childhood Favorable Prognosis Hodgkin Lymphoma. NCI

Thesaurus. Code C114806.

A Hodgkin lymphoma with favorable prognosis that occurs during childhood. 